
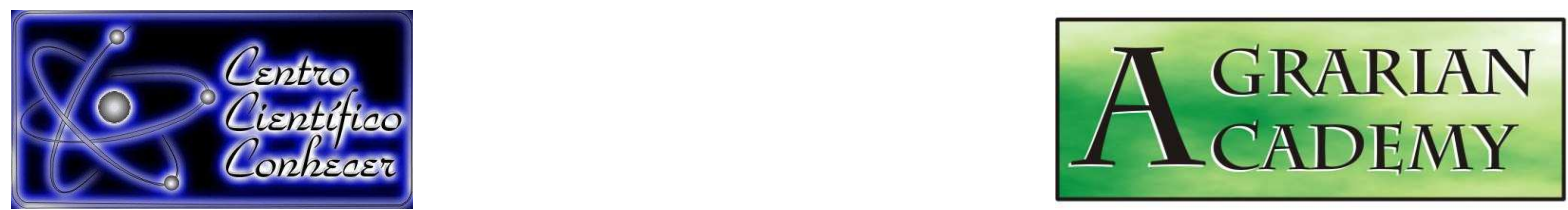

\title{
FILOSSILICATOS: EFEITOS NO CRESCIMENTO E NA NUTRIÇÃO DE PLANTAS DE MILHO E NO TEOR DE SILÍCIO DO SOLO
}

\section{Guilherme Felisberto ${ }^{1 *}$, Rafhael Mendes Fehr ${ }^{2}$, Leandro José Grava de Godoy ${ }^{3}$, Patrícia Aparecida de Carvalho Felisberto ${ }^{1}$}

${ }^{1}$ Engenheiros Agrônomos, Mestrandos em Agronomia - Universidade Federal de Goiás - UFG - Regional Jataí, Jataí - GO, Brasil. *gfelisberto@outlook.com;

${ }^{2}$ Engenheiro Agrônomo, Mestre em Ciências (Solos e Nutrição de Plantas), Piracicaba - SP, Brasil;

${ }^{3}$ Engenheiro Agrônomo, Professor Doutor em Agronomia - Universidade Estadual Paulista "Júlio de Mesquita Filho" - UNESP - Câmpus de Registro, Registro - SP, Brasil.

\section{Recebido em: 05/12/2014 - Aprovado em: 14/12/2014 - Publicado em: 15/12/2014}

\section{RESUMO}

A importância da adubação silicatada está relacionada com os benefícios que o silício é capaz de promover, como tolerância a metais pesados, diminuição na incidência de pragas e doenças, aumento da produtividade, tolerância a seca, entre outros. Objetivou-se com este trabalho avaliar o efeito de filossilicatos no acúmulo de fitomassa, nutrientes e silício, nos estádios iniciais de plantas de milho, comparado à wollastonita. O experimento foi instalado e conduzido em casa de vegetação da Universidade Estadual Paulista, UNESP, localizada no município de Registro, SP e foi constituído de 10 tratamentos estabelecidos em delineamento inteiramente casualizado, em esquema fatorial $(2 \times 5)$, com cinco repetições. 0 primeiro fator corresponde aos dois tipos de solos (Latossolo Amarelo e Argissolo Vermelho Amarelo) e o segundo fator aos cinco tratamentos (controle, $0 \mathrm{~kg} \mathrm{ha}^{-1} \mathrm{Si}$; W13 - wollastonita, $13 \mathrm{~kg} \mathrm{ha}{ }^{-1} \mathrm{Si}$; W26 - wollastonita, $26 \mathrm{~kg} \mathrm{ha}^{-1} \mathrm{Si}$; F13 filossilicatos, $13 \mathrm{~kg} \mathrm{ha}^{-1} \mathrm{Si}$; F26 - filossilicatos, $26 \mathrm{~kg} \mathrm{ha}^{-1} \mathrm{Si}$ ). No Argissolo, os filossilicatos aumentaram a produção de fitomassa fresca, seca e conteúdo de silício na parte aérea das plantas de milho em relação ao tratamento com wollastonita e ao controle. O maior teor de $\mathrm{Si}$ em relação ao controle $\left(6,2 \mathrm{~g} \mathrm{~kg}^{-1}\right)$ foi obtido no tratamento com filossilicatos na dose de $13 \mathrm{~kg} \mathrm{ha}^{-1}$ de Si $\left(9,8 \mathrm{~g} \mathrm{~kg}^{-1}\right)$. Os maiores acúmulos de massa e Si nas plantas, em função da aplicação de filossilicatos, foram observados no Argissolo, apesar deste apresentar teor de Si maior do que no Latossolo.

PALAVRAS-CHAVE: fertilizante silicatado, silício, wollastonita, Zea mays L.

\section{PHYLLOSILICATES: EFFECT IN GROWTH AND NUTRITION OF CORN PLANTS AND IN THE SOIL CHEMICAL PROPERTIES}

\footnotetext{
ABSTRACT

Importance of silicon fertilization is related to the benefits that silicon is able to promote tolerance to heavy metals, reduce the incidence of pests and diseases, AGRARIAN ACADEMY, Centro Científico Conhecer - Goiânia, v.1, n.02; p. 60 
increased productivity, drought tolerance, among others. The objective of this study was to evaluate the phyllosilicates effect on biomass formation, nutrients and silicon on the early stages of corn plants compared to wollastonite. Experiment was installed and conducted in a greenhouse located at the Universidade Estadual Paulista, UNESP, in Registro, SP. Consisting of 10 treatments established in a randomized block design in scheme factorial $(2 \times 5)$, with five replications. First factor corresponds to the two types of soil (Oxisol and Ultisol) and the second factor, five treatments (control, $0 \mathrm{~kg} \mathrm{ha}^{-1} \mathrm{Si}$; wollastonite $\mathrm{W} 13,13 \mathrm{~kg} \mathrm{ha}^{-1} \mathrm{Si}$; wollastonite W26, $26 \mathrm{~kg} \mathrm{ha}^{-1} \mathrm{Si}$; phyllosilicates F13, $13 \mathrm{~kg} \mathrm{ha}^{-1} \mathrm{Si}$; phyllosilicates F26, $26 \mathrm{~kg} \mathrm{ha}^{-1} \mathrm{Si}$ ). In Ultisol, phyllosilicates increased production of fresh, dry biomass and silicon content in shoots of corn compared to treatment with wollastonite and control. Highest $\mathrm{Si}$ content compared to control $\left(6.2 \mathrm{~g} \mathrm{~kg}^{-1}\right)$ was obtained with $13 \mathrm{~kg} \mathrm{ha}^{-1} \mathrm{Si}$ of phyllosilicates $\left(9.8 \mathrm{~g} \mathrm{~kg}^{-1}\right)$. The greatest accumulation mass and $\mathrm{Si}$ in plants by applying phyllosilicates were observed in Ultisol, although this display $\mathrm{Si}$ content higher than Oxisol.

KEYWORDS: silicate mineral, silicon, wollastonite, Zea mays L.

\section{INTRODUÇÃO}

A utilização de rochas moídas aplicadas sobre o solo é empregada desde os primórdios da agricultura, porém o tema tem-se desenvolvido com maior velocidade no Brasil após a crise do setor de fertilizantes que ocorreu no ano 2008. Verifica-se na literatura, pesquisas com rochas moídas, principalmente as classificadas como silicáticas que têm sido estudadas como fontes de potássio. Entretanto, algumas rochas silicáticas como os filossilicatos apresentam potencial como fonte de outros elementos minerais. Segundo LUZ et al. (2010), nas rochas silicáticas ocorrem também outros elementos que podem contribuir para o desenvolvimento dos vegetais, como por exemplo o silício.

$\mathrm{Na}$ solução do solo encontra-se silício sob a forma pouco dissociada, $\mathrm{Si}(\mathrm{OH})_{4}$, porém sujeita a interagir ativamente com o complexo sortivo. Desse modo, a sílica dissolvida nos solos é um soluto ativo e não um componente passivo, que será perdido por lixiviação logo após as rochas serem intemperizadas (MCKEAGUE \& CLINE, 1963).

A importância da aplicação de silício ao solo está relacionada com os benefícios que este elemento é capaz de promover, como a tolerância a metais pesados, diminuição na incidência de pragas (GOUSSAIN et al., 2002) e doenças (REZENDE et al., 2009), aumento da produtividade, (MARSCHNER, 1995), tolerância a seca (OLIVEIRA, et al., 2010), resistência ao acamamento (ÁVILA et al., 2010) e promover dessorção de fósforo dos sítios de adsorção, embora esse efeito dependerá da mineralogia da fração argila e atividade do Si na solução do solo (CESSA et al., 2011), entre outros.

$\mathrm{Na}$ agricultura brasileira, a principal fonte de silício empregada nas lavouras, tem sido os silicatos de cálcio e magnésio, oriundos de escória de siderurgia uma vez que são as fontes mais baratas e abundantes de silicatos (STOCCO et al., 2010). Além de ser necessário utilizar em grandes quantidades devido ao baixo teor de $\mathrm{Si}$, outro fator restritivo dessas fontes é a presença de metais pesados (KORNDÖRFER, 2004).

As escórias de siderurgia têm como característica alterar a reação do solo (pH) como foi verificado por NOGUEIRA et al. (2012), fato que dificulta o emprego destas fontes em solos que já estão corrigidos através da calagem (MADEIROS et 
al., 2009). GODOY et al. (2009) apresentam como alternativa para esses problemas o uso de fontes naturais de silício como os filossilicatos, que são compostos minerais silicatados, como o fertilizante Microton $\AA^{\circledR}$ que apresenta seis tipos de filossilicatos, balanceados de forma natural e que disponibiliza $60 \%$ de $\mathrm{SiO}_{2}$, não proporcionando alteração de $\mathrm{pH}$ e podendo também ser utilizado na agricultura orgânica.

O milho pode ser considerado uma espécie que apresenta grande capacidade de absorver o silício, haja vista que, plantas acumuladoras de silício possuem teor foliar acima de 1\%, e não acumuladoras, teor de silício menor que 0,5\% (MA et al., 2001). Esse elemento é absorvido de forma ativa pelas plantas como ácido monossilícico $\left(\mathrm{H}_{4} \mathrm{SiO}_{4}\right)$, transportado por meio do xilema, depositado e polimerizado na forma de sílica amorfa $\left(\mathrm{Si}_{2} \cdot \mathrm{nH}_{2} \mathrm{O}\right)$ nas paredes celulares da epiderme de folhas, colmos e cascas ou também pode formar estruturas silicificadas, os fitólitos (RAVEN, 2001). Segundo MA \& YAMAJI (2006) em gramíneas supridas com silício, há um acúmulo de sílica amorfa na parede celular das folhas, levando à formação de uma dupla camada de sílica-cutícula.

Os principais trabalhos encontrados na literatura em relação à utilização de silício na cultura do milho, em sua maioria, são com fontes provenientes de escória siderúrgica para avaliar o desenvolvimento de pragas na cultura e déficit hídrico, deixando a produção de fitomassa e grãos, muitas vezes, em segundo plano. Com o presente trabalho, objetivou-se avaliar o efeito de filossilicatos no acúmulo de fitomassa, nutrientes e silício nos estádios iniciais de plantas de milho, comparado à wollastonita.

\section{MATERIAL E MÉTODOS}

O experimento foi instalado e conduzido em casa de vegetação, modelo 'teto em arco' com, aproximadamente, 3,0 m de pé-direito, construída com lateral telada e teto de polietileno difusor de luz de 150 micras, situada no Câmpus de Registro da Universidade Estadual Paulista, UNESP, localizado no município de Registro, SP. As coordenadas geográficas da área são $24^{\circ} 29^{\prime} 15^{\prime \prime} \mathrm{S}, 47^{\circ} 50^{\prime} 37^{\prime \prime} \mathrm{O}$ e altitude de $25 \mathrm{~m}$. O experimento foi constituído de 10 tratamentos estabelecidos em delineamento inteiramente casualizado em esquema fatorial $(2 \times 5)$, com cinco repetições. O primeiro fator corresponde aos dois tipos de solos (Latossolo Amarelo e Argissolo Vermelho Amarelo) e o segundo fator aos cinco tratamentos (Tabela 1).

TABELA 1. Descrição das fontes de Si e doses aplicadas.

\begin{tabular}{cccc}
\hline Tratamento & Fonte de Si & $\begin{array}{c}\text { Dose de Silício } \\
\mathrm{kg} \mathrm{ha}^{-1}\end{array}$ & $\begin{array}{c}\text { Dose da Fonte } \\
\mathrm{kg} \mathrm{ha}^{-1}\end{array}$ \\
\hline 1 & Controle (CONT) & 0 & 0 \\
2 & Wollastonita (W13) & 13 & 56,5 \\
3 & Wollastonita (W26) & 26 & 113 \\
4 & Filossilicatos (F13) & 13 & 50 \\
5 & Filossilicatos (F26) & 26 & 100 \\
\hline \hline
\end{tabular}

A wollastonita é classificada como metassilicato de cálcio, mundialmente empregada como fonte padrão em estudos com silício e apresenta $23,0 \%$ de Si e $42,4 \%$ de $\mathrm{CaO}$. A fonte utilizada trata-se de um pó a base de filossilicatos e comercializado como Microton ${ }^{\circledR}$, contendo $605 \mathrm{~g} \mathrm{~kg}^{-1}$ de $\mathrm{SiO}_{2}$ equivalente a $26 \%$ de 
$\mathrm{Si} ; 22 \mathrm{~g} \mathrm{~kg}^{-1}$ de $\mathrm{Fe}_{2} \mathrm{O}_{3} ; 21 \mathrm{~g} \mathrm{~kg}^{-1}$ de $\mathrm{Na}_{2} \mathrm{O} ; 19 \mathrm{~g} \mathrm{~kg}^{-1}$ de $\mathrm{CaO} ; 20 \mathrm{~g} \mathrm{~kg}^{-1}$ de $\mathrm{MgO}$ e $14 \mathrm{~g}$ $\mathrm{kg}^{-1}$ de $\mathrm{K}_{2} \mathrm{O}$, proveniente da moagem de 6 tipos de filossilicatos. Este tipo de mineral é caracterizado por possuir lâminas alternadas de tetraedros de silício e octaedros de alumínio, ligadas entre si por átomos de oxigênio. A estrutura em lâminas é formada pela polimerização de unidades de silício (tetraedros de silício) e de alumínio (octaedros de alumínio), que se dá em duas dimensões, formando um plano ou uma lâmina, diferindo de outros silicatos como o quartzo e o feldspato (tectossilicatos), cuja polimerização é tridimensional (AZEVEDO et al., 2012).

Foi coletado solo da camada de 20 a $40 \mathrm{~cm}$ de dois tipos de solo (Latossolo Amarelo e Argissolo Vermelho Amarelo) com as seguintes características: Latossolo - 148; 192; $660 \mathrm{~g} \mathrm{~kg}^{-1}$ de argila, silte e areia total, respectivamente, $\mathrm{pH} 5,3$; MOS de $4 \mathrm{~g} \mathrm{dm}^{-3} ; \mathrm{P}$ de $17 \mathrm{mg} \mathrm{dm}^{-3} ; 4,2 ; 24 ; 12 ; 55,4 \mathrm{mmol}_{\mathrm{c}} \mathrm{dm}^{-3}$ de $\mathrm{K}, \mathrm{Ca}, \mathrm{Mg}$ e CTC, respectivamente e 0,$78 ; 1,4 ; 53,0 ; 12,7 ; 1,5 \mathrm{mg} \mathrm{dm}^{-3}$ de $\mathrm{B}, \mathrm{Cu}, \mathrm{Fe}, \mathrm{Mn}$ e $\mathrm{Zn}$, respectivamente. Argissolo - 337; 395; $268 \mathrm{~g} \mathrm{~kg}^{-1}$ de argila, silte e areia total, respectivamente, $\mathrm{pH} 4,7 ;$ MOS de $13 \mathrm{~g} \mathrm{dm}^{-3}$; $\mathrm{P}$ de $17 \mathrm{mg} \mathrm{dm}^{-3} ; 3,6 ; 36 ; 17 ; 91,9$ $\mathrm{mmol}_{\mathrm{c}} \mathrm{dm}^{-3}$ de K, Ca, Mg e CTC, respectivamente e 1,04;4,4;122;53,5;10,9 mg $\mathrm{dm}^{-3}$ de $\mathrm{B}, \mathrm{Cu}, \mathrm{Fe}, \mathrm{Mn}$ e $\mathrm{Zn}$, respectivamente. Os extratores utilizados em ambos os solos para a determinação de $\mathrm{P}, \mathrm{K}, \mathrm{Ca}$ e $\mathrm{Mg}$ foram através de resina e para $\mathrm{Mn}, \mathrm{Fe}$, $\mathrm{Cu}$ e $\mathrm{Zn}$, utilizou-se DTPA. Os solos foram peneirados e adicionados em vasos de polietileno com capacidade de $3 \mathrm{dm}^{3}$ e em seguida corrigidos com calcário dolomítico, ficando em incubação por 20 dias, para elevar a saturação por bases a $80 \%$.

A adubação de plantio foi realizada de modo igual para ambos os solos: 50 ; 200 e $180 \mathrm{mg} \mathrm{dm}^{-3}$, de nitrogênio, fósforo e potássio, tendo como fontes nitrato de amônio $(34 \%$ de $\mathrm{N})$, superfosfato simples $\left(18 \%\right.$ de $\left.\mathrm{P}_{2} \mathrm{O}_{5}\right)$ e cloreto de potássio $(60 \%$ $\mathrm{K}_{2} \mathrm{O}$ ), respectivamente. Após pesados, misturou-se a estes fertilizantes as fontes de silício e suas respectivas doses, simulando a utilização das fontes de silício em formulados comerciais. Em cada vaso, os fertilizantes foram aplicados, incorporados e homogeneizados ao solo.

O híbrido de milho utilizado foi o 2B587 e a irrigação foi realizada por meio de rega conforme as necessidades hídricas da cultura, repondo a água evapotranspirada, buscando manter o teor de água a $70 \%$ da capacidade de campo. A parte aérea das plantas de milho foi coletada 30 dias após a semeadura (DAS) e acondicionadas em sacos plásticos, na qual foram imediatamente pesadas em balança eletrônica de precisão para obtenção dos dados de fitomassa fresca. Posteriormente a este processo, o material vegetal foi levado à estufa de circulação de ar forçada a $6^{\circ} \mathrm{C}$ por 48 horas para desidratação e determinação da fitomassa seca. De cada vaso, coletou-se amostras de solo que foram secas ao ar e peneiradas em malha de $2 \mathrm{~mm}$. Foram determinados os teores de macronutrientes, micronutrientes e silício na fitomassa seca da parte aérea. O conteúdo de silício acumulado na parte aérea do milho foi calculado a partir da multiplicação do teor de silício pela sua respectiva fitomassa seca. No solo determinou-se apenas o teor de silício.

Os resultados obtidos nas avaliações, foram submetidos à análise de variância utilizando-se o teste $\mathrm{F}$ a $5 \%$ de probabilidade e, para comparação de médias, adotou-se o teste Tukey a $5 \%$ de probabilidade. 


\section{RESULTADOS E DISCUSSÃO}

A fitomassa fresca (Figura 1) e seca (Figura 2) foi maior no Argissolo Vermelho-Amarelo quando comparado com o Latossolo Amarelo, com exceção no tratamento referente a $26 \mathrm{~kg} \mathrm{ha}^{-1}$ de wollastonita. Esse efeito proporcionou menor extração de nutrientes pelas plantas de milho (Tabela 2 e 3). No Argissolo, a dose de $13 \mathrm{~kg} \mathrm{ha}^{-1}$ de Si, via filossilicatos, proporcionou maior acúmulo que o tratamento controle e o tratamento com a respectiva dose de wollastonita, apresentando ganhos de fitomassa fresca de $81,35 \mathrm{~g}$ e $69,6 \mathrm{~g}$, respectivamente. O mesmo comportamento foi observado na fitomassa seca, em que a aplicação de wollastonita proporcionou maior produção de fitomassa que o controle enquanto os filossilicatos apresentaram valores superiores. LIMA et al. (2011) também verificaram aumento da fitomassa seca de folhas, caules e raízes de plantas de milho quando aplicado o silicato de sódio via solução nutritiva. FEHR et al. (2010) estudando os filossilicatos supracitados relatam que os mesmos são capazes de disponibilizar o silício para as plantas, permitindo-as usufruírem dos efeitos benéficos deste elemento, principalmente no aumento de produção de fitomassa fresca e seca, e sem alterar o $\mathrm{pH}$ do solo. Por outro lado, trabalhando com os mesmos filossilicatos do presente trabalho, FARIA et al. (2013) verificaram que doses de silício aplicadas modificaram as respostas da composição morfológica do rabanete porém não foram capazes de afetar no ganho de produtividade.

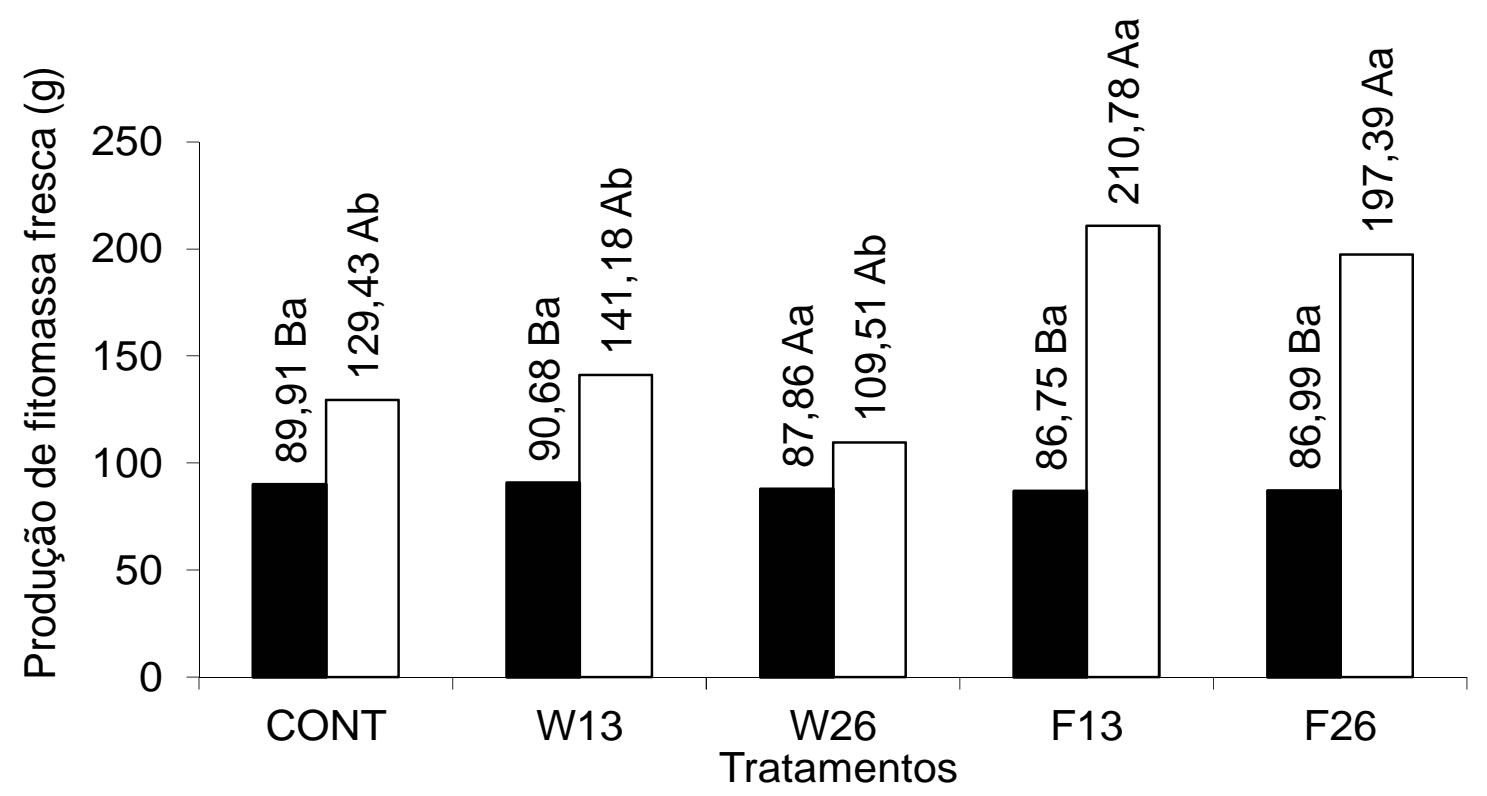

FIGURA 1. Fitomassa fresca de plantas de milho aos 30 dias após semeadura em dois solos com aplicação de fontes e duas doses de silício. Letras maiúsculas iguais não diferem entre si em relação aos solos e minúsculas iguais não diferem entre si em relação as fontes e doses - Tukey $(P<0,05)$. (Cont - Controle, $0 \mathrm{~kg} \mathrm{ha}^{-1}$ de Si; W13 wollastonita, $13 \mathrm{~kg} \mathrm{ha}^{-1}$ de Si; W26 - wollastonita, $26 \mathrm{~kg} \mathrm{ha}^{-1}$ de Si; F13 - filossilicatos, $13 \mathrm{~kg} \mathrm{ha}^{-1}$ de Si; e F26 - filossilicatos, $26 \mathrm{~kg} \mathrm{ha}^{-1}$ de Si). (Registro, SP, 2011). 


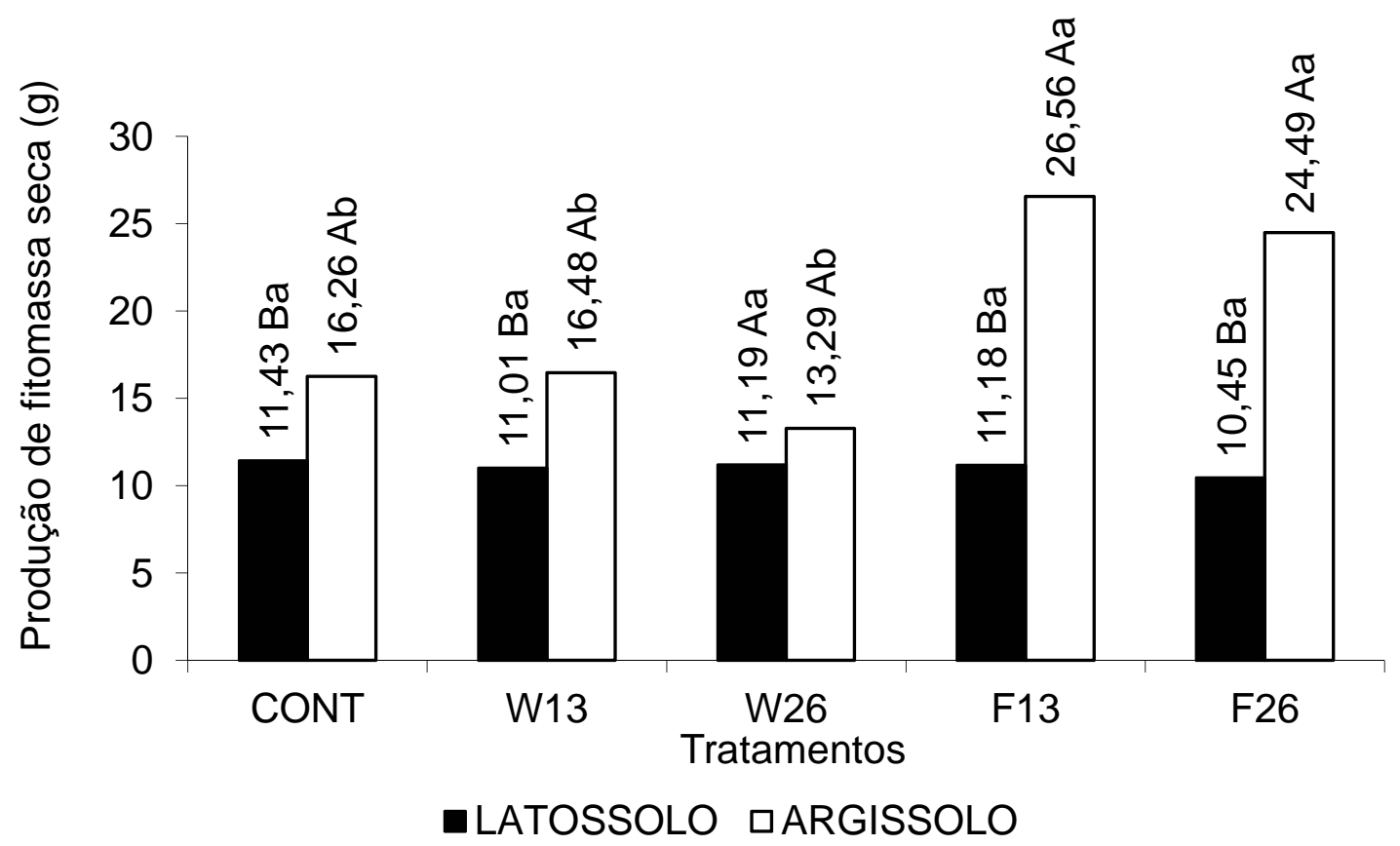

FIGURA 2. Fitomassa seca de plantas de milho aos 30 dias após semeadura em dois solos com aplicação de fontes e duas doses de silício. Letras maiúsculas iguais não diferem entre si em relação aos solos e minúsculas iguais não diferem entre si em relação as fontes e doses Tukey $(\mathrm{P}<0,05)$. (Cont - Controle, $0 \mathrm{~kg} \mathrm{ha}^{-1}$ de Si; W13 - wollastonita, $13 \mathrm{~kg} \mathrm{ha}^{-1}$ de Si; W26 - wollastonita, $26 \mathrm{~kg} \mathrm{ha}^{-1}$ de Si; F13 filossilicatos, $13 \mathrm{~kg} \mathrm{ha}^{-1}$ de Si; e F26 - filossilicatos, $26 \mathrm{~kg} \mathrm{ha}^{-1}$ de Si). (Registro, SP, 2011).

TABELA 2. Extração dos macronutrientes pelas plantas de milho cultivadas, em relação as fontes e doses (Registro, SP, 2011).

\begin{tabular}{ccccccc}
\hline \multirow{2}{*}{ Tratamentos } & $\mathrm{N}$ & $\mathrm{P}$ & $\mathrm{K}$ & $\mathrm{Ca}$ & $\mathrm{Mg}$ & $\mathrm{S}$ \\
& - & $-\mathrm{c}$ Latossolo & Amarelo \\
\hline CONT & $180 \mathrm{Bab}^{1}$ & $10,8 \mathrm{Ba}$ & $88 \mathrm{Ba}$ & $88 \mathrm{Aa}$ & $133,7 \mathrm{Aa}$ & $19,7 \mathrm{Ba}$ \\
W13 & $186 \mathrm{Ba}^{-}$ & $10,7 \mathrm{Ba}$ & $87 \mathrm{Ba}$ & $85 \mathrm{Aa}$ & $133,8 \mathrm{Aa}$ & $18,6 \mathrm{Ba}$ \\
W26 & $177 \mathrm{Bab}$ & $10,2 \mathrm{Aa}$ & $77 \mathrm{Ba}$ & $87 \mathrm{Aa}$ & $135,2 \mathrm{Aa}$ & $18,7 \mathrm{Aa}$ \\
F13 & $138 \mathrm{Bb}$ & $10,4 \mathrm{Ba}$ & $90 \mathrm{Ba}$ & $70 \mathrm{Ba}$ & $104,8 \mathrm{Ab}$ & $16,6 \mathrm{Ba}$ \\
F26 & $140 \mathrm{Bab}$ & $9,8 \mathrm{Ba}$ & $88 \mathrm{Ba}$ & $67 \mathrm{Ba}$ & $100,2 \mathrm{Ab}$ & $16,8 \mathrm{Ba}$ \\
\hline \multicolumn{7}{c}{ Argissolo Vermelho Amarelo } \\
\hline CONT & $241 \mathrm{Acd}$ & $15,8 \mathrm{Ab}$ & $690 \mathrm{Abc}$ & $84 \mathrm{Ac}$ & $45,1 \mathrm{Bab}$ & $28,2 \mathrm{Ab}$ \\
W13 & $270 \mathrm{Abc}$ & $15,9 \mathrm{Ab}$ & $745 \mathrm{Ab}$ & $88 \mathrm{Abc}$ & $46,5 \mathrm{Bab}$ & $25,7 \mathrm{Ab}$ \\
W26 & $215 \mathrm{Ad}$ & $13,4 \mathrm{Ab}$ & $590 \mathrm{Ac}$ & $73 \mathrm{Ac}$ & $37,8 \mathrm{Bb}$ & $21,5 \mathrm{Ab}$ \\
F13 & $329 \mathrm{Aa}$ & $28,5 \mathrm{Aa}$ & $1028 \mathrm{Aa}$ & $129 \mathrm{Aa}$ & $74,2 \mathrm{Ba}$ & $40,8 \mathrm{Aa}$ \\
F26 & $309 \mathrm{Aab}$ & $25,0 \mathrm{Aa}$ & $955 \mathrm{Aa}$ & $113 \mathrm{Aa}$ & $65,7 \mathrm{Bab}$ & $37,4 \mathrm{Aa}$ \\
\hline
\end{tabular}

'Letras maiúsculas iguais não diferem entre si em relação aos solos e minúsculas iguais não diferem entre si em relação as fontes e doses - Tukey $(P<0,05)$. (Cont - Controle, $0 \mathrm{~kg} \mathrm{ha}^{-1}$ de Si; W13 wollastonita, $13 \mathrm{~kg} \mathrm{ha}^{-1}$ de Si; W26 - wollastonita, $26 \mathrm{~kg} \mathrm{ha}^{-1}$ de Si; F13 - filossilicatos, $13 \mathrm{~kg} \mathrm{ha}^{-1}$ de $\mathrm{Si}$; e F26 - filossilicatos, $26 \mathrm{~kg} \mathrm{ha}^{-1}$ de Si). 
TABELA 3. Extração dos micronutrientes pelas plantas de milho cultivadas, em relação as fontes e doses (Registro, SP, 2011).

\begin{tabular}{|c|c|c|c|c|c|}
\hline Tratamentos & B & $\mathrm{Cu}$ & $\mathrm{Fe}$ & $\mathrm{Mn}$ & $\mathrm{Zn}$ \\
\hline & \multicolumn{5}{|c|}{ Latossolo Amarelo } \\
\hline CONT & $265 \mathrm{Ba}$ & $55 \mathrm{Aa}$ & $1103 \mathrm{Aa}$ & $176 \mathrm{Ba}$ & $273 \mathrm{Ba}$ \\
\hline W13 & $224 \mathrm{Ba}$ & $35 \mathrm{Bab}$ & $1090 \mathrm{Aa}$ & $155 \mathrm{Ba}$ & $256 \mathrm{Ba}$ \\
\hline W26 & $312 \mathrm{Aa}$ & $29 \mathrm{Bb}$ & $1034 \mathrm{Aa}$ & $157 \mathrm{Ba}$ & $259 \mathrm{Ba}$ \\
\hline $\mathrm{F} 13$ & $197 \mathrm{Ba}$ & $36 \mathrm{Bab}$ & $750 \mathrm{Ba}$ & $129 \mathrm{Ba}$ & $210 \mathrm{Ba}$ \\
\hline \multirow[t]{2}{*}{ F26 } & $253 \mathrm{Ba}$ & $31 \mathrm{Bab}$ & $706 \mathrm{Ba}$ & $109 \mathrm{Ba}$ & $164 \mathrm{Ba}$ \\
\hline & \multicolumn{5}{|c|}{ Argissolo Vermelho Amarelo } \\
\hline CONT & $390 \mathrm{Ab}$ & $69 \mathrm{Ab}$ & $1207 \mathrm{Aa}$ & $857 \mathrm{Abc}$ & $1322 \mathrm{Abc}$ \\
\hline W13 & $494 \mathrm{Aab}$ & $81 \mathrm{Aab}$ & $1325 \mathrm{Aa}$ & $778 \mathrm{Abc}$ & $1451 \mathrm{Ab}$ \\
\hline W26 & $394 \mathrm{Aab}$ & $63 \mathrm{Ab}$ & $1100 \mathrm{Aa}$ & 729 Ac & $1093 \mathrm{Ac}$ \\
\hline $\mathrm{F} 13$ & $592 \mathrm{Aa}$ & $105 \mathrm{Aa}$ & $1400 \mathrm{Aa}$ & $1469 \mathrm{Aa}$ & $2101 \mathrm{Aa}$ \\
\hline F26 & $601 \mathrm{Aa}$ & $83 \mathrm{Aab}$ & $1714 \mathrm{Aa}$ & $1014 \mathrm{Ab}$ & $1602 \mathrm{Ab}$ \\
\hline
\end{tabular}

'Letras maiúsculas iguais não diferem entre si em relação aos solos e minúsculas iguais não diferem entre si em relação as fontes e doses - Tukey $(P<0,05)$. (Cont - Controle, $0 \mathrm{~kg} \mathrm{ha}^{-1}$ de Si; W13 wollastonita, $13 \mathrm{~kg} \mathrm{ha}^{-1}$ de Si; W26 - wollastonita, $26 \mathrm{~kg} \mathrm{ha}^{-1}$ de Si; F13 - filossilicatos, $13 \mathrm{~kg} \mathrm{ha}^{-1} \mathrm{de}$ $\mathrm{Si}$; e F26 - filossilicatos, $26 \mathrm{~kg} \mathrm{ha}^{-1}$ de Si).

No Latossolo Amarelo, arenoso, foi observada ausência de efeito em relação ao acúmulo de nutrientes nas plantas cultivadas sob adubação de filossilicatos. Verifica-se na literatura, de maneira geral, que solos arenosos respondem com maior frequência e positivamente à aplicação de silício em relação aos argilosos (CHAVES et al., 2013). Entretanto, no Argissolo, de textura média-argilosa a extração de nitrogênio, fósforo, potássio, cálcio e enxofre foram superiores, independentemente das doses de filossilicatos empregadas (Tabela 2). Os nutrientes manganês e zinco tiveram extração superior, quando as plantas foram cultivadas com filossilicatos na dose de $13 \mathrm{~kg} \mathrm{ha}^{-1}$ de Si (Tabela 3). A maior resposta apresentada no Argissolo (mais argiloso) pela aplicação dos filossilicatos os tornam uma fonte destinadas àqueles solos onde as fontes tradicionais de silício não proporcionam os ganhos desejados.

O conteúdo de silício na parte aérea das plantas de milho (Figura 3) no Argissolo foi superior quando comparado com o Latossolo. Assim, como a fitomassa seca e fresca, o conteúdo de silício na planta no Latossolo, não apresentou diferença estatística entre as fontes e doses, porém verificou-se visualmente os efeitos relatados por MARSCHNER (1995), referente ao silício promover a melhor arquitetura das plantas (folhas mais eretas), e assim diminuir o auto sombreamento. Espera-se que ao permitir que a folha permaneça mais ereta, aumente a área de exposição à luz solar e a eficiência na captura de radiação solar, porém esse efeito não foi suficiente para promover maior fitomassa no Latossolo. Entretanto, no Argissolo, a aplicação de wollastonita, na maior dose, e de filossilicatos, independente da dose, proporcionou maior fitomassa (Figura 1 e 2) e conteúdo de silício acumulado (Figura 3) que os demais tratamentos. 


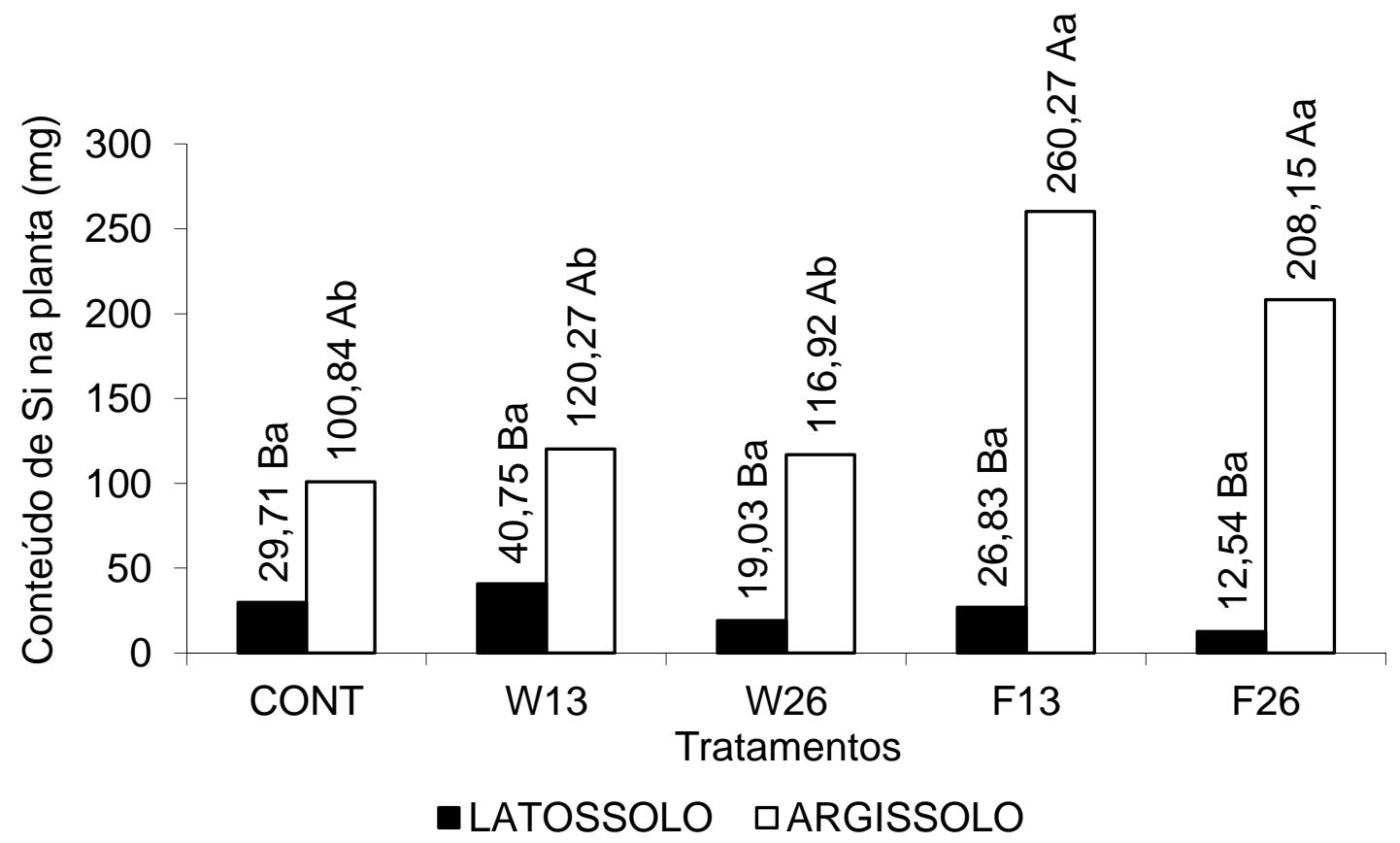

FIGURA 3. Conteúdo de silício de plantas de milho aos 30 dias após semeadura em dois solos com aplicação de fontes e duas doses de silício. Letras maiúsculas iguais não diferem entre si em relação aos solos e minúsculas iguais não diferem entre si em relação as fontes e doses Tukey $(\mathrm{P}<0,05)$. (Cont - Controle, $0 \mathrm{~kg} \mathrm{ha}^{-1}$ de Si; W13 - wollastonita, $13 \mathrm{~kg} \mathrm{ha}^{-1}$ de Si; W26 - wollastonita, $26 \mathrm{~kg} \mathrm{ha}^{-1}$ de Si; F13 filossilicatos, $13 \mathrm{~kg} \mathrm{ha}^{-1}$ de Si; e F26 - filossilicatos, $26 \mathrm{~kg} \mathrm{ha}^{-1}$ de Si). (Registro, SP, 2011).

O teor de silício nas plantas de milho (Figura 4), foi inferior quando cultivadas sob o Latossolo, no qual o teor de $\mathrm{Si}$ nos tratamentos com fontes de $\mathrm{Si}$ não diferiu do controle. No Argissolo, o maior teor de Si em relação ao controle $(6,2$ $\mathrm{g} \mathrm{kg}^{-1}$ ) e a wollastonita (W13) foi obtido no tratamento com filossilicatos, na dose de $13 \mathrm{~kg} \mathrm{ha}^{-1}\left(9,8 \mathrm{~g} \mathrm{~kg}^{-1}\right)$. GOUSSAIN et al. (2002), em trabalho com aplicação foliar de silício no milho, observaram teor foliar médio de $6,5 \mathrm{~g} \mathrm{~kg}^{-1}$ de Si. Este valor é superior a todos os tratamentos encontrados no presente trabalho, quando comparados com as plantas cultivadas no Latossolo, no entanto, é menor do que nas plantas dos tratamentos com aplicação de silício no Argissolo. CARVALHO et al. (1999), em trabalho com sorgo, presenciaram o aumento do teor de silício nas folhas, que passou de 4 para $6 \mathrm{~g} \mathrm{~kg}^{-1}$ quando feita a adubação silicatada, valores bem inferiores aos encontrados nas plantas de milho do tratamento com filossilicatos na dose de $13 \mathrm{~kg} \mathrm{ha}^{-1}$ de Si. 


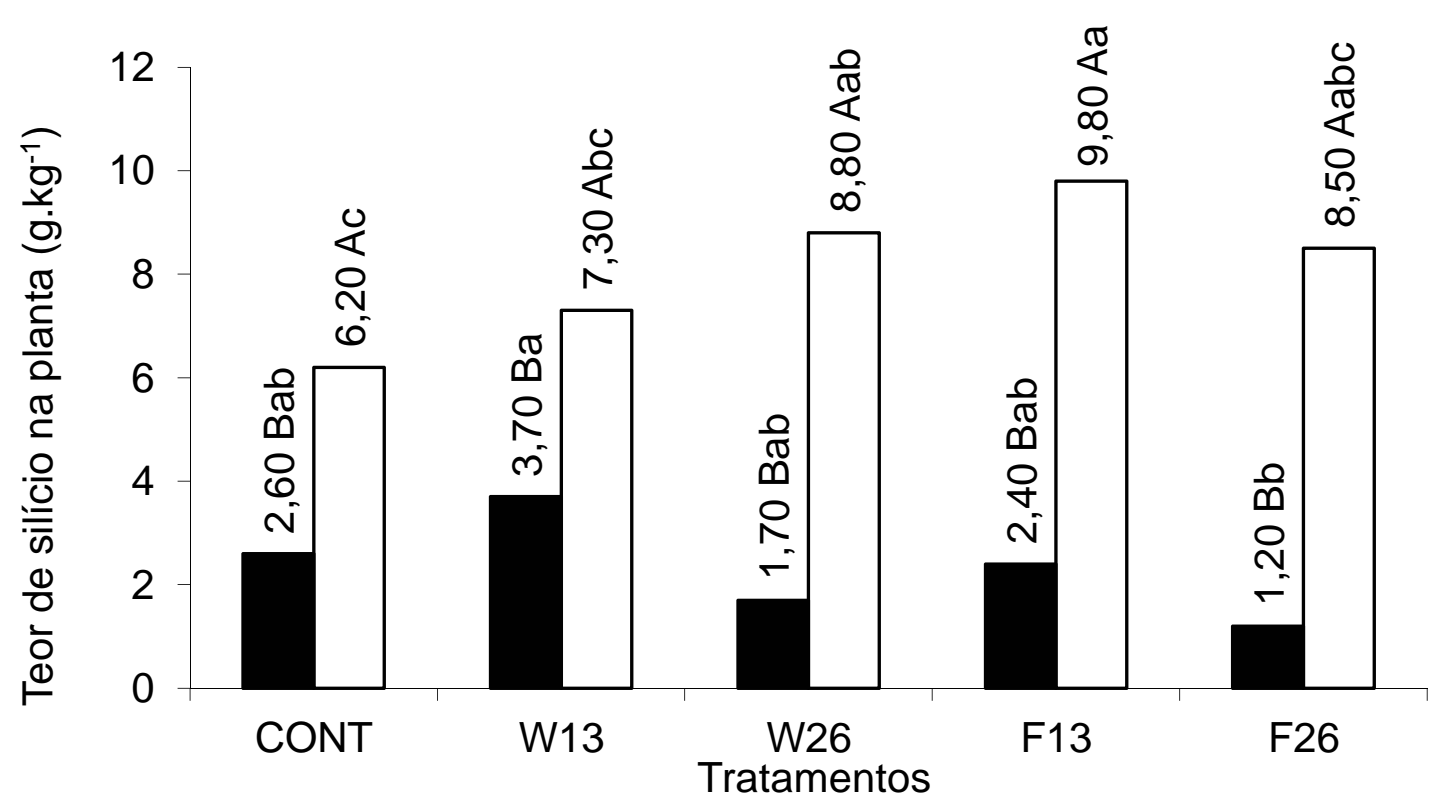

FIGURA 4. Teor de silício em plantas de milho aos 30 dias após semeadura em dois solos com aplicação de fontes e duas doses de silício. Letras maiúsculas iguais não diferem entre si em relação aos solos e minúsculas iguais não diferem entre si em relação as fontes e doses Tukey $(\mathrm{P}<0,05)$. (Cont - Controle, $0 \mathrm{~kg} \mathrm{ha}^{-1}$ de Si; $\mathrm{W} 13$ - wollastonita, $13 \mathrm{~kg} \mathrm{ha}^{-1}$ de Si; W26 - wollastonita, $26 \mathrm{~kg} \mathrm{ha}^{-1}$ de Si; F13 filossilicatos, $13 \mathrm{~kg} \mathrm{ha}^{-1}$ de Si; e F26 - filossilicatos, $26 \mathrm{~kg} \mathrm{ha}^{-1}$ de Si). (Registro, SP, 2011).

O teor de Si no solo foi menor no Latossolo em comparação com o Argissolo (Tabela 4), devido ao menor intemperismo. Segundo BARBOSA FILHO et al. (2004), durante a intemperização dos solos ocorre dessilicificação do material de origem, o que pode contribuir para a maior disponibilidade de silício. Somente o tratamento com a wollastonita, na dose $13 \mathrm{~kg} \mathrm{ha}^{-1}$ de Si, proporcionou maior teor de silício no Argissolo comparado ao tratamento controle, entretanto este aumento foi pouco expressivo. O tratamento com filossilicatos, na mesma dose, obteve menor teor de silício, provavelmente devido à maior absorção deste elemento pelas plantas.

TABELA 4. Teor de silício nos solos em função de fontes de Si e doses (extrator $\mathrm{CaCl}_{2}$ ). (Registro, SP, 2011).

\begin{tabular}{|c|c|c|}
\hline Tratamentos & \multicolumn{2}{|c|}{ - } \\
\hline CONT & $2,7 \mathrm{Ba}^{1}$ & $19,1 \mathrm{Abc}$ \\
\hline W13 & 2,7 Ba & 19,9 Аа \\
\hline W26 & $2,5 \mathrm{Ba}$ & $19,4 \mathrm{Aab}$ \\
\hline F13 & $2,5 \mathrm{Ba}$ & $18,4 \mathrm{Ac}$ \\
\hline F26 & $2,6 \mathrm{Ba}$ & $19,4 \mathrm{Aab}$ \\
\hline
\end{tabular}

'Letras maiúsculas iguais não diferem entre si em relação aos solos e minúsculas iguais não diferem entre si em relação as fontes e doses - Tukey $(P<0,05)$. (Cont - Controle, $0 \mathrm{~kg} \mathrm{ha}^{-1}$ de Si; W13 wollastonita, $13 \mathrm{~kg} \mathrm{ha}^{-1}$ de Si; W26 - wollastonita, $26 \mathrm{~kg} \mathrm{ha}^{-1}$ de Si; F13 - filossilicatos, $13 \mathrm{~kg} \mathrm{ha}^{-1} \mathrm{de}$ $\mathrm{Si}$; e F26 - filossilicatos, $26 \mathrm{~kg} \mathrm{ha}^{-1}$ de Si). 


\section{CONCLUSÕES}

Somente no Argissolo, os filossilicatos aumentaram a produção de fitomassa fresca, seca e conteúdo de silício na parte aérea da cultura do milho em relação ao tratamento com wollastonita e ao controle.

O maior teor de $\mathrm{Si}$ em relação ao controle $\left(6,2 \mathrm{~g} \mathrm{~kg}^{-1}\right)$ foi obtido no tratamento com filossilicatos na dose de $13 \mathrm{~kg} \mathrm{ha}^{-1}$ de Si $\left(9,8 \mathrm{~g} \mathrm{~kg}^{-1}\right)$.

Os maiores acúmulos de massa e Si nas plantas, em função da aplicação de filossilicatos, foram observados no Argissolo, apesar deste apresentar teor de $\mathrm{Si}$ maior do que no Latossolo.

\section{REFERÊNCIAS}

ÁVILA, F. W.; BALIZA, D. P.; FAQUIN, V.; ARAÚJO, J. L.; RAMOS, S. J. Interação entre silício e nitrogênio em arroz cultivado sob solução nutritiva. Revista Ciência Agronômica, v. 41, n. 2, p. 184-190, 2010.

AZEVEDO, A. C.; PEDRON, F. A.; SARTOR, L. R.; CASARINI, P. G. Filossilicatos 2:1 com hidróxi entre camadas em solos: estado atual do conhecimento e das perspectivas de pesquisa. Revista Ciências Agrárias, v. 55, n. 3, p. 236-243, 2012.

BARBOSA FILHO, M. P.; ZIMMERMANN, F. J. P.; SILVA, O. F. Influência da escória silicatada na acidez do solo e na produtividade de grãos do arroz de terras altas. Ciência e Agrotecnologia, v. 28, n. 2, p. 323-331, 2004.

CARVALHO, S. P., MORAES J. C.; CARVALHO, J. G. Efeito do silício na resistência do sorgo (Sorghum bicolor) ao pulgão-verde Schizaphis graminum (Rond.) (Homoptera: Aphididae). Anais da Sociedade Entomológica do Brasil, v. 28, n. 3, p. 505-510, 1999.

CESSA, R. M. A.; NOVELINO, J. O.; VITORINO, A. C. T.; MAUAD, M. Absorção de fósforo e crescimento do sorgo em função da aplicação de silício e fósforo em Latossolo Vermelho distroférrico. Revista de Ciências Agrárias, v. 34, n. 1, p. 135142, 2011.

CHAVES, L. H. G; DANTAS NETO, J.; FERNANDES, J. D.; ALVES, H. S.; RIBEIRO, P. H. P. Adubação silicatada e lâminas de irrigação no crescimento e produção da cana-de-açúcar. Global Science and Technology, v. 6, n. 3, p. 67-78, 2013.

FARIA, L. M. V.; GOMES, M. B.; SILVA, T. R. Resposta morfológica do rabanete à aplicação de diferentes doses de silício na linha de semeadura. Revista Eletrônica Interdisciplinar da Univar, v. 2, n. 10, p. 121-128, 2013.

FEHR, R. M.; SOUSA, R. M.; FELISBERTO, G.; GODOY, L. J. G. Exportação de nutrientes e silício pela alface, submetida a doses de composto mineral silicatado, em dois solos. In: Fertbio; XXIX Reunião Brasileira de Fertilidade do Solo e Nutrição de Plantas 2010. Anais... Guarapari. Sociedade Brasileira de Ciências do Solo: Guarapari, 2010. CD-ROM 1. 
GODOY, L. J. G.; PINHEIRO, D. R.; MENDONÇA, J. C.; FRANÇA, F. G. Teor de silício e de nutrientes no solo e nas folhas de bananeira submetida a doses de silicato de cálcio e magnésio no Vale do Ribeira, In: XXXII Congresso Brasileiro de Ciências do Solo. Anais... Fortaleza. Sociedade Brasileira de Ciências do Solo: Fortaleza, 2009. CD-ROM 1.

GOUSSAIN, M. M.; MORAES, J. C.; CARVALHO, J. G.; NOGUEIRA, N. L.; ROSSI, M. L. Efeito da aplicação de silício em plantas de milho no desenvolvimento biológico da lagarta-do-cartucho Spodoptera frugiperda (J.E. Smith) (Lepidoptera: Noctuidae). Neotropical Entomology, v. 31, n. 2, p. 305-310, 2002.

KORNDÖRFER, G. H.; NOLLA, A.; OLIVEIRA, L. A. Silício no solo e na planta. 2004. Uberlândia: GPSi-ICIAG-UFU. 24p. (GPSi-ICIAG-UFU. Boletim Técnico, 031‥ Edição).

LIMA, M. A.; CASTRO, V. F.; VIDAL, J. B.; ENÉAS FILHO, J. Aplicação de silício em milho e feijão-de-corda sob estresse salino. Revista Ciência Agronômica, v. 42, n. 2, p. 398-403, 2011

LUZ, A. B.; LAPIDO-LOUREIRO, F. E.; SAMPAIO, J. A.; CASTILHOS, Z. C.; BEZERRA, M. S. Rochas, minerais e rotas tecnológicas para a produção de fertilizantes alternativos. In: FERNANDES, F. R. C.; LUZ, A. B.; CASTILHOS, Z. C. Agrominerais para o Brasil. Rio de Janeiro: CETEM, 2010. p. 61-88.

MA, J. F.; MIYAKE, Y.; TAKAHASHI, E. Silicon as fa beneficial element for crop plant. In: DATNOFF, L. E.; SNYDER, G.; KORNDÖRFER, G. H. (Eds.) Silicon in Agriculture. New York: Elsevier Science, 2001. p. 17-39.

MA, J. F.; YAMAJI, N. Silicon uptake and accumulation in higher plants. Trends in Plant Science, v. 11, n. 8, p. 392-397, 2006

MADEIROS, L. B.; ALMEIDA, G. M., AQUINO, B. F. Aplicação de escória siderúrgica no solo: efeito sobre o fósforo solúvel. Engenharia Ambiental, v. 6, n. 1, p. 27-37, 2009.

MARSCHNER, $\mathrm{H}$. Mineral nutrition of higher plants. $2^{\mathrm{a}}$ ed. Londres: Academics Press, 1995. 889p.

McKEAGUE, J. A.; CLINE, M. G. Silica in soils. II. The adsorption of monosilicic acid by soil and by other substances. Canadian Journal of Soil Science, v. 43, n. 1, p. 83-96, 1963.

NOGUEIRA, N. O.; TOMAZ, M. A.; ANDRADE, F. V.; REIS, E. F.; BRINATE, S. V. B.; Influência da aplicação de dois resíduos industriais nas propriedades químicas de dois solos cultivados com café arábica. Revista Ciência Agronômica, v. 43, n. 1, p. 11-21, 2012.

OLIVEIRA, C. M. R.; PASSOS, R. R.; ANDRADE, F. V.; REIS, E. F.; STURM, G. M.; SOUZA, R. B. Corretivos da acidez do solo e níveis de umidade no desenvolvimento 
da cana-de-açúcar. Revista Brasileira de Ciências Agrárias, v. 5, n. 1, p. 25-31, 2010.

RAVEN, J. A. Silicon transport at the cell and tissue level. In: DATNOFF, L. E.; SNYDER, G.; KORNDÖRFER, G. H. (Eds.) Silicon in Agriculture. New York: Elsevier Science, 2001. p. 41-55.

REZENDE, D. C.; RODRIGUES, F. A.; CARRÉ-MISSIO, V.; SCHURT, D. A.; KAWAMURA, I. K.; KORNDÖRFER, G. H. Effect of root and foliar applications of silicone on brown spot development in rice. Australasian Plant Pathology, v. 38, p. 67-73, 2009.

STOCCO, F. C.; PASSOS, R. R.; ANDRADE, F. V.; REIS, E. F.; LIMA, J. S. S.; SANTOS, D. A.; MACHADO, R. V. Uso de escórias de siderurgia na produção de matéria seca e perfilhamento de duas gramíneas do gênero Brachiaria em um Latossolo Vermelho-Amarelo. Bioscience Journal, v. 26, n. 2, p. 240-248, 2010. 